\title{
Response to “Does Insufficient Sleep Increase the Body Mass Index in Adolescents?"
}

\author{
Qing Miao ${ }^{a}$ b Yehong Yang ${ }^{a}$ Yiming $\mathrm{Li}^{\mathrm{a}}$ \\ ${ }^{a}$ Department of Endocrinology and Metabolism, Fudan University, Huashan Hospital, Shanghai, China; \\ ${ }^{b}$ Department of Endocrinology and Metabolism/Fudan University, Huashan North Hospital, Shanghai, China
}

\section{Dear Editor,}

We are very grateful to Dr. Orozco and Dr. Shukla for their interest and suggestions to our article [1]. In response to the questions raised in the letter entitled "Does Insufficient Sleep Increase the Body Mass Index in Adolescents?" we have carefully evaluated and tried our best to answer them, hoping to resolve the authors' confusions.

We checked the original data about the mean BMI of overweight and obese people, and we are very sorry to find that there were some errors, so we want to correct them here. The mean BMI of overweight men was $25.6 \pm$ 1.1 and that of overweight women was $25.2 \pm 1.0$. The mean BMI of obese men was $30.5 \pm 2.4$ and that of obese women was $30.4 \pm 2.3$. We apologize for these errors and any confusion these may have caused. Table 1 showed the demographic characteristics of participants. The correction of the data in Table 1 does not affect the expression of other tables and contents in the article. Furthermore, this correction does not affect our conclusion about the relationship between sleeping time and BMI.

Our study was a cluster sampling study from the realworld evidence (RWE). We collected data of all freshmen in the multidisciplinary university. The National Sleep Foundation (NSF) [2] and the American Academy of Sleep Medicine [3] recommend a healthy sleep duration

karger@karger.com www.karger.com/ofa

Karger"
(C) 2021 The Author(s)

Published by S. Karger AG, Basel

This article is licensed under the Creative Commons AttributionNonCommercial-NoDerivatives 4.0 International License (CC BYNC-ND) (http://www.karger.com/Services/OpenAccessLicense) Usage and distribution for commercial purposes as well as any distribution of modified material requires written permission. based on age. For adolescents, the shortest sleep duration is defined as a sleep duration of $<6 \mathrm{~h}$; and the recommended sleeping time is defined as at least $8 \mathrm{~h}$ in a $24-\mathrm{h}$ period. So, the sleeping time was divided into 3 categories based on the duration, $<6 \mathrm{~h}, 6-8 \mathrm{~h}$ and $>8 \mathrm{~h}$ per day. There was a significant difference in the number of people in different categories of sleeping time, which just reflected the actual situation.

An unadjusted univariate model and a multivariate model were used for the estimation of association between sleeping time and BMI. As an influencing factor, age was included in the univariate analysis, but as you said, age was not found to be statistically significant, so age was not included in the multivariate analysis. The factors with significant differences in univariate analysis were included in multivariate analysis. The multivariate model used in this study was adjusted for sex, diet control, and maternal obesity. The sleeping time was not considered as one of the confounders.

We developed the questionnaire according to the Three Factor Eating Questionnaire (TFEQ-18) to investigate whether the subjects control their diet, and we investigated how many times per week the subjects eat

Qing Miao and Yehong Yang contributed equally to this work.
Correspondence to:

Yiming Li, yimingli@fudan.edu.cn 
breakfast and how many pounds of vegetables they eat every day. The estimation of past diet patterns include a retrospective report or a recent diet recall. Subjects were asked to recall their eating habits for 2 years in order to avoid eating fluctuations in a short time $[4,5]$.

As limitations we mentioned that not all essential parameters are included in our study, such as physical activity and sedentary behavior. We did not collect information about metabolic equivalent (MET) in this study. We will collect information about the amount of physical activity in the follow-up prospective study.

The relationship between body fat percentage and $\mathrm{BMI}$ is not our main research question, so we did not discuss it. Different authorities have given different suggestions on the criteria of body fat percentage, including the criteria of WHO and ASBP, there is no unified recognition of authority. Therefore, we used the three tertiles to classify the body fat percentage.

In the discussion section, we mentioned that "The significant difference between sleeping time $6-8$ and $>8 \mathrm{~h}$ only exists in BMI categories based on overweight in the univariate and multivariate analyses. Irrelevant relation between either $<6$ and $>8$ h or $6-8$ and $>8 \mathrm{~h}$ are observed in BMI categories based on obesity. This suggests that the overweight stage is a critical period of weight management intervention by changing sleeping time. If adolescents have entered the obesity stage, the effect size of lifestyle intervention might be significantly reduced." So, what we emphasized was that "The overweight stage is a critical period of weight management intervention by changing sleeping time. If adolescents have entered the obesity stage, the effect size of lifestyle intervention might be significantly limited." This was combined with the following sentence that "Longer sleeping time was associated with a lower BMI in Chinese freshmen, even after adjustment for multiple confounders."

\section{Conflict of Interest Statement}

The authors have no conflicts of interest to declare.

\section{Funding Sources}

We acknowledge financial support from the National Natural Science Foundation of China (81800691, 81471083, 81670751, 81000329), National Key R\&D Program of China (2016YFC1305105), Shanghai Municipal Commission of Health and Family Planning (No. 20164Y0041, 20144Y0070, ZHYYZXYJHZX-1-01), Scientific Research Project supported by Huashan Hospital, Fudan University (No. 2013QD10).

\section{Author Contributions}

Q.M. and Y.H.Y. edited the manuscript; Y.M.L. reviewed and gave final approval.

\section{References}

Miao et al.: Sleeping Time and BMI of Freshmen
1 Yang Y, Miao Q, Zhu X, Qin L, Gong W, Zhang S, et al. Sleeping Time, BMI, and Body Fat in Chinese Freshmen and Their Interrelation. Obes Facts. 2020;13(2):179-90.

2 Hirshkowitz M, Whiton K, Albert SM, Alessi C, Bruni O, DonCarlos L, et al. National Sleep Foundation's sleep time duration recommendations: methodology and results summary. Sleep Health. 2015 Mar;1(1):40-3.

3 Paruthi S, Brooks LJ, D'Ambrosio C, Hall WA, Kotagal S, Lloyd RM, et al. Recommend- ed Amount of Sleep for Pediatric Populations: A Consensus Statement of the American Academy of Sleep Medicine. J Clin Sleep Med. 2016 Jun;12(6):785-6.

4 Kuzma JW, Lindsted KD. Determinants of eight-year diet recall ability. Epidemiology. 1990 Sep;1(5):386-91.

5 Pereira RA, Koifman S. [Using food frequency questionnaire in past dietary intake assessment].RevSaudePublica.1999Dec;33(6):610 21. Portuguese. 